\title{
Pengaruh Jumlah Pemasangan Soil Nailing Terhadap Peningkatan Faktor Keamanan Lereng
}

\author{
Liong Andreas Setiawan Budiharjo ${ }^{1}$, David Christian Mahardhika², \\ Maria Wahyuni ${ }^{3}$, Rinda Karlinasari ${ }^{4}$ \\ email: ${ }^{1}$ andreassetiawan536@gmail.com, ${ }^{2}$ dcmahardhika@gmail.com, \\ ${ }^{3}$ maria@unika.ac.id, ${ }^{4}$ rkarlinasari@gmail.com
}

Program Studi Teknik Sipil, Fakultas Teknik, Unika Soegijapranata, Semarang, Universitas Katolik

Soegijapranata; Jl. Pawiyatan Luhur IV/1 Bendan Dhuwur Semarang 50234, 024-8441555

\begin{abstract}
Abstrak
Tanah longsor terjadi pada lereng yang tidak stabil. Lereng pada Jalan Burangrang Raya, Kelurahan Jangli, Kecamatan Tembalang, Kota Semarang merupakan salah satu lokasi yang mengalami tanah longsor. Penelitian ini bertujuan untuk mengetahui pengaruh jumlah pemasangan soil nailing terhadap peningkatan faktor keamanan lereng. Soil nailing berdiameter $10 \mathrm{~cm}$ dipasang dengan panjang $11 \mathrm{~m}$. Baja tulangan untuk soil nailing berdiameter $25 \mathrm{~mm}$ dengan kuat leleh sebesar $390 \mathrm{MPa}$. Pemasangan soil nailing divariasi dengan jumlah 2 baris, 3 baris, dan 5 baris. Jarak pemasangan soil nailing kearah horisontal sebesar $2 \mathrm{~m}$, sedangkan kearah vertikal untuk soil nailing 2 baris, 3 baris, dan 5 baris secara berurutan sebesar 4,74 m; 4,74 m; dan 2,37 m. Hasil penelitian menunjukkan nilai faktor keamanan lereng sebelum diperkuat sebesar 1,06. Faktor keamanan lereng dengan perkuatan soil nailing sebanyak 2 baris, 3 baris, dan 5 baris pada jangka pendek secara berurutan sebesar 3,18; 3,27; dan 3,43. Pada jangka panjang faktor keamanan lereng dengan perkuatan soil nailing sebanyak 2 baris, 3 baris, dan 5 baris secara berurutan sebesar 2,31; 2,62; dan 2,76. Faktor keamanan lereng dengan perkuatan soil nailing meningkat lebih dari dua kali nilai faktor keamanan lereng tanpa perkuatan. Besarnya faktor keamanan lereng berbanding lurus dengan jumlah soil nailing yang terpasang pada lereng.
\end{abstract}

Kata kunci : : Lereng, Soil Nailing, Faktor Keamanan

\begin{abstract}
Landslides occur on unstable slopes. The slope on Burangrang Raya street, Jangli, Tembalang, Semarang is one of the locations that experienced a landslides. The slope on Burangrang Raya street is one of the locations that experienced a landslide. This study aims to determine the effect of the number of soil nailing installations on increasing slope safety factors. The installed soil nailing on that slope has $10 \mathrm{~cm}$ in diameter with a length of

$11 \mathrm{~m}$. Reinforcing steel for soil nailing has $25 \mathrm{~mm}$ in diameter with a yield strength of $390 \mathrm{Mpa}$. Installation of soil nailing varies with the amount of 2 rows, 3 rows, and 5 rows. The installed soil nailing on that slope has $10 \mathrm{~cm}$ in diameter with a length of $11 \mathrm{~m}$. Reinforcing steel for soil nailing has $25 \mathrm{~mm}$ in diameter with a yield strength of $390 \mathrm{MPa}$. Installation of soil nailing varies with the amount of 2 lines, 3 lines, and 5 lines. The distance of installing soil nailing towards horizontal is $2 \mathrm{~m}$, while vertical direction for soil nailing is 2 rows, 3 rows, and 5 rows respectively $4.74 \mathrm{~m} ; 4.74 \mathrm{~m}$; and 2.37 $m$. The results showed the value of the slope safety factor in natural conditions is 1.06. Slope safety factor with reinforcement of soil nailing as much as 2 rows, 3 rows, and 5 rows in the short run respectively 3.18; 3.27; and 3.43. In the long run, the slope safety factor is by strengthening soil nailing as much 2 lines, 3 lines, and 5 lines in a row of 2.31; 2.62; and 2.76. Slope safety factor with soil nailing reinforcement increased more than twice the value of slope safety factor without reinforcement. The magnitude of the slope safety factor is directly proportional to the amount of soil nailing installed on the slope.
\end{abstract}

Keywords: Slope, Soil Nailing, Safety Factor 


\section{PENDAHULUAN}

\subsection{Latar Belakang}

Kondisi topografi di Indonesia yang memiliki perbedaan elevasi menyebabkan terbentuknya lereng. Lereng dengan tanah tidak stabil dapat terjadi longsor misalnya pada lereng di Jalan Burangrang Raya, Kelurahan Jangli, Kecamatan Tembalang, Kota Semarang. Lokasi lereng tersebut ditunjukkan pada Gambar 1.

Penanganan longsor yang terjadi pada lereng dapat dilakukan dengan berbagai cara salah satunya dengan pemasangan soil nailing. Banyaknya soil nailing yang dipasang akan mempengaruhi peningkatan faktor keamanan lereng. Faktor keamanan lereng dengan soil nailing dapat dihitung dengan bantuan aplikasi komputer misalnya dengan aplikasi PLAXIS.

PLAXIS merupakan salah satu aplikasi geoteknik berbasis elemen hingga. Aplikasi tersebut dapat digunakan untuk mensimulasikan perilaku tanah dari pemodelan yang sederhana hingga yang kompleks serta pemodelan terhadap perbaikan tanah yang dilakukan. Oleh sebab itu, aplikasi tersebut dapat digunakan untuk mengetahui faktor keamanan lereng pada Jalan Burangrang Raya.

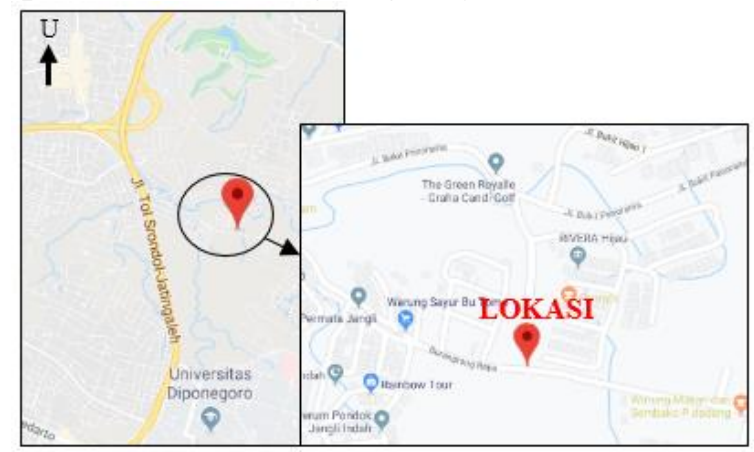

Gambar 1 Lokasi Jalan Burangrang Raya (Sumber: https://www.google.co.id/maps)

\subsection{Perumusan Masalah}

Masalah dalam penelitian ini dapat dirumuskan menjadi bagaimana pengaruh jumlah pemasangan soil nailing terhadap peningkatan faktor keamanan lereng di Jalan Burangrang Raya.

\subsection{Batasan Masalah}

Permasalahan dalam penelitian ini dilakukan pembatasan masalah berupa:

a. Data parameter tanah menggunakan nilai korelasi dengan hasil bor yang ada.

b. Analisis stabilitas lereng dilakukan terhadap potongan melintang lereng Jalan Burangrang Raya.

c. Analisis stabilitas lereng menggunakan PLAXIS V.8.2 tanpa memperhitungkan adanya rembesan air, drainase lereng, kondisi tanah ekspansif, dan beban luar.

d. Tulangan untuk soil nailing menggunakan baja berdiameter $25 \mathrm{~mm}$ dengan panjang $11 \mathrm{~m}$ dan kuat leleh sebesar $390 \mathrm{MPa}$.

e. Analisis stabilitas lereng jangka panjang menggunakan asumsi pengurangan kuat geser sebesar $20 \%$ dari kuat geser asli.

\subsection{Tujuan Penelitian}

Tujuan dari penelitian ini yaitu untuk mengetahui pengaruh jumlah pemasangan soil nailing terhadap peningkatan faktor keamanan lereng di Jalan Burangrang Raya.

\section{TINJAUAN PUSTAKA}

\subsection{Tanah Longsor}

Tanah longsor menurut Nandi (2007) merupakan suatu peristiwa berpindahnya material pembentuk lereng ke bawah atau keluar lereng. Tanah longsor banyak terjadi pada daerah yang memiliki tanah yang labil dan memiliki kontur yang relatif curam. Tanah yang labil kebanyakan berupa tanah residu yang terbentuk dari pelapukan batuan vulkanik. Tanah tersebut memiliki ciri yaitu tanah cenderung gembur sehingga mudah runtuh ketika kandungan air dalam tanah tinggi.

Tanah longsor akan terjadi apabila perlawanan terhadap pergeseran tanah terlampaui. Menurut Hardiyatmo (2010), suatu lereng dapat mengalami kelongsoran karena disebabkan oleh:

a. Perubahan posisi muka air,

b. Kenaikan tekanan lateral oleh air,

c. Penurunan tahanan geser tanah,

d. Penambahan beban pada lereng, 
e. Gempa bumi atau getaran berlebihan,

f. Penggalian tanah pada kaki lereng dan mempertajam kemiringan lereng.

\subsection{Stabilitas Lereng}

Lereng merupakan permukaan tanah yang tidak horisontal serta menghubungkan antara permukaan tanah yang rendah dengan permukaan tanah yang lebih tinggi seperti yang ditunjukkan pada Lereng memiliki resiko kelongsoran yang tinggi. Potensi kelongsoran pada lereng dapat diketahui dengan melakukan analisis stabilitas lereng. Lereng berpotensi terjadi longsor apabila berdasarkan analisis stabilitas lereng diperoleh nilai faktor keamanan lereng kurang dari yang disyaratkan. Biasanya faktor keamanan untuk lereng diambil sebesar 1,2 sampai dengan 1,5 yang dapat dihitung dengan limit equilibrium method dan Shear Strength Reduction.

\section{Limit Equilibrium Method}

Metode keseimbangan gaya (limit equilibrium method) dapat digunakan untuk menganalisis stabilitas lereng. Menurut Abramson et al. (2001), analisis stabilitas lereng dengan prinsip tersebut dapat dibagi menjadi beberapa metode analisis yaitu infinite slope analysis, planar surface analysis, circular surface analysis, dan method of slice.

Menurut Hadiyatomo (2010), nilai faktor keamanan lereng $(F)$ merupakan hasil perbandingan gaya yang menahan pada lereng $(\tau)$ dengan gaya yang mendorong pada lereng $\left(\tau_{d}\right)$. Nilai faktor keamanan tersebut dapat dicari dengan persamaan:

$F=\frac{\tau}{\tau_{d}}$

Menurut teori Mohr-Coulomb, tahanan geser tahan maksimum sepanjang bidang longsornya $(\tau)$ dan tegangan geser yang terjadi akibat beban tanah dan bebanbeban lainnya $\left(\tau_{d}\right)$ memiliki bentuk umum sebagai berikut:

$\tau=c+\sigma \operatorname{tg} \phi$

$\tau_{d}=c_{d}+\sigma \operatorname{tg} \phi_{d}$

\section{Shear Strength Reduction Method}

Shear Strength Reduction (SSR) Method merupakan salah satu teknik yang digunakan untuk analisis stabilitas lereng dengan metode elemen hingga atau Finite Element Method (FEM). Metode SSR dilakukan dengan melakukan pengurangan nilai kohesi dan sudut geser tanah. Metode SSR memiliki konsep sederhana yaitu dengan mengurangi kekuatan geser material hingga lereng mengalami kegagalan (Hammah et al., 2005).

Berikut langkah-langkah untuk analisis $S S R$ :

a. Menentukan shear strength reduction ratio $(r)$,

b. Menentukan parameter kuat geser yang baru dengan persamaan berikut:

$$
\begin{aligned}
& c_{r}=\frac{c}{r} . . . \ldots \ldots \ldots . . . . . \\
& \tan \phi_{r}=\frac{\tan \phi}{r} .
\end{aligned}
$$

c. Menghitung faktor keamanan dari parameter kuat geser yang baru.

\subsection{Soil Nailing}

Pemasangan soil nailing merupakan salah satu metode yang digunakan untuk memperkuat lereng sehingga lebih stabil. Soil nailing terdiri dari beberapa komponen yang dapat dilihat pada Gambar 2. Komponen penyusun soil nailing terdiri dari nail bar, nail head, grout, dan centralizer.

Soil nailing harus direncanakan agar baja tulangan yang dipasang tidak putus serta soil nailing tidak tercabut saat menahan gaya tarik yang terjadi. Kuat tarik material soil nailing (baja tulangan) direncanakan dengan persamaan:

$T_{d}=\phi_{k} \phi_{n} \phi_{t} f_{y} A_{p}$

Nilai faktor reduksi beban $\left(\phi_{k}\right)$, klasifikasi desain struktur $\left(\phi_{n}\right)$, dan faktor reduksi material tendons $\left(\phi_{t}\right)$ secara berurutan dapat dilihat pada Tabel 1, Tabel 2, dan Tabel 3.

Soil nailing perlu dianalisis kekuatannya terhadap gaya cabut. Gaya cabut pada soil nailing dapat dihitung menggunakan persamaan:

$T^{*}=\phi_{n} \phi_{b} \pi d L_{f} \tau_{u}$ 
Nilai $\phi_{n}$ dan $\phi_{b}$ dapat dilihat pada Tabel 2 dan Tabel 3. Diameter lubang grout (d) dan panjang nail bars $\left(L_{f}\right)$ pada Persamaan (7) dalam satuan meter.

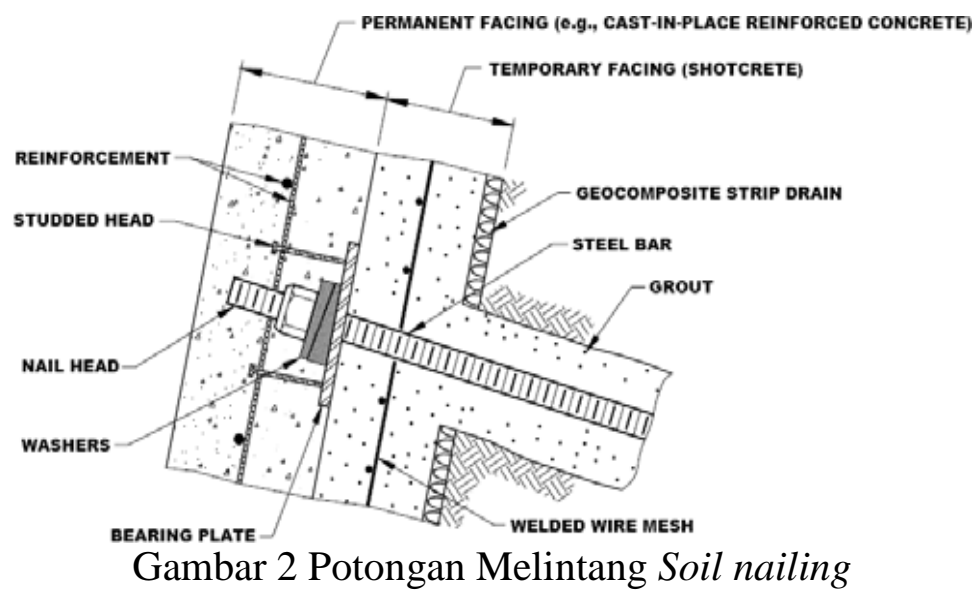

(Sumber: FHWA-SA-93-026, 1993)

Tabel 1 Faktor Reduksi Beban

\begin{tabular}{|c|c|c|}
\hline Anchor Category & $\begin{array}{c}\text { Structure } \\
\text { Classification }\end{array}$ & $\begin{array}{l}\text { Importance } \\
\text { Category } \\
\text { Reduction } \\
\text { Faktor } \\
\quad \phi_{k}\end{array}$ \\
\hline $\begin{array}{l}1 \text { Temporary anchors where the service life is less than six } \\
\text { months of a structure classification A structure, that is, } \\
\text { where failure would have few serious consequences and } \\
\text { would not endanger public safety, e.g. short-term pile test } \\
\text { loading using anchors as a reaction system }\end{array}$ & A & 0,9 \\
\hline $\begin{array}{l}2 \text { Temporary anchors with a service life of up to five years } \\
\text { of a structure classification B structure, that is, where, } \\
\text { although the consequences of load failure are quite } \\
\text { serious, there is no danger to public safety without } \\
\text { adequate warning, e.g. retaining wall tie backs }\end{array}$ & B & 0,85 \\
\hline $\begin{array}{l}3 \text { Any permanent anchors and also temporary anchors of a } \\
\text { structure classification C structure, that is, where the } \\
\text { consequences of failure are serious, e.g. temporary } \\
\text { anchors for main cables of a suspension bridge, or as a } \\
\text { reaction for lifting heavy structural members }\end{array}$ & $\mathrm{C}$ & 0,8 \\
\hline
\end{tabular}

Sumber: AS4678-2002, 2002

Tabel 2 Klasifikasi Desain Struktur

\begin{tabular}{cc}
\hline $\begin{array}{c}\text { Structure } \\
\text { Classification }\end{array}$ & $\begin{array}{c}\text { Design Faktor, } \\
\left(\phi_{\boldsymbol{n}}\right)\end{array}$ \\
\hline $\mathrm{A}$ & 1,1 \\
\hline $\mathrm{B}$ & 1,0 \\
\hline $\mathrm{C}$ & 0,9
\end{tabular}

Sumber: AS4678-2002, 2002
Tabel 3 Faktor Reduksi Material

\begin{tabular}{ccc}
\hline $\begin{array}{c}\text { Faktor } \\
\text { Reduksi }\end{array}$ & Material & Koefisien \\
\hline$\phi_{t}$ & Tendon & 0.9 \\
\hline$\phi_{b}$ & Bond & 0.7
\end{tabular}

Sumber: AS4678-2002, 2002 


\subsection{Analisis Shear Strength Reduction Method Menggunakan PLAXIS \\ PLAXIS merupakan suatu program} dalam bidang geoteknik untuk memodelkan tanah dan mensimulasikan perilaku dari tanah. Program tersebut menggunakan metode elemen hingga dengan teknik shear strength reduction dalam menganalisis pemodelan yang dibuat. Analsis dilakukan dengan melakukan tahapan input data dan pengaturan kalkulasi data.

\section{Input Data PLAXIS}

Data yang perlu dimasukkan saat membuat pemodelan menggunakan aplikasi PLAXIS berupa penggambaran model, pemilihan suatu opsi, dan pengisian suatu nilai nilai tertentu. Input berupa penggambaran model pada PLAXIS contohnya penggambaran stratigrafi tanah, sedangkan input berupa pemilihan suatu opsi pada PLAXIS misalnya pemilihan material model Mohr-Coulomb. Input berupa pengisian suatu nilai contohnya pengisian nilai parameter tanah.

\section{Kalkulasi Data pada PLAXIS}

Tahap kalkulasi data dilakukan setelah tahap input pada PLAXIS dengan beberapa pengaturan analisis sesuai analisis yang diperlukan. Beberapa kalkulasi yang dilakukan pada PLAXIS yaitu plastic calculation, consolidation analysis, dan phic reduction. Plastic calculation digunakan untuk menghitung deformasi elastis-plastis pada model. Consolidation analysis digunakan apabila ada pengaruh konsolidasi tanah pada model yang dibuat. Phi-c reduction digunakan untuk menghitung nilai faktor keamanan dari model yang dibuat.

\section{METODE PENELITIAN}

Suatu metode diperlukan dalam melakukan sebuah penelitian agar penelitian yang dilakukan dapat berjalan dengan baik dan juga sistematis. Metode yang digunakan pada penelitian ini dapat dirumuskan melalui diagram alir (flow chart) penelitian pada Gambar 3.

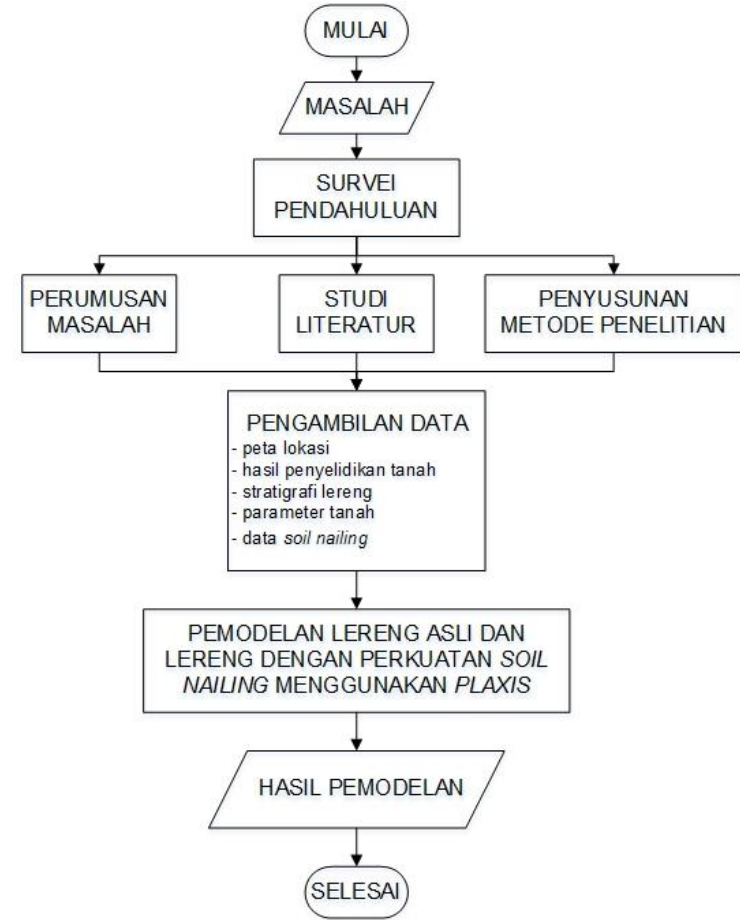

Gambar 3 Diagram Alir Penelitian

Berdasarkan diagram alir pada Gambar 3, tahapan penelitian yang dilakukan sebagai berikut:

a. Survei pendahuluan

Kegiatan survei pendahuluan dilakukan dengan meninjau langsung lokasi permasalahan yang hendak diteliti. Pada penelitian ini, kegiatan survei pendahuluan dilakukan pada lereng di Jalan Burangrang Raya. Hasil yang diperoleh dari survei pendahuluan ini berupa kondisi awal lereng, penyebab lereng longsor, dan proses terjadinya longsoran.

b. Perumusan masalah, studi literatur, dan penyusunan metode penelitian

Kegiatan ini dilakukan setelah melakukan suvei pendahuluan. Perumusan masalah dilakukan untuk merumuskan latar belakang masalah, rumusan dan batasan masalah. Tujuan dan manfaat penelitian juga turut dirumuskan pada tahap ini.

Studi literatur merupakan suatu tahapan penelitian dalam mempelajari literatur dari berbagai sumber yang dapat digunakan untuk menangani masalah yang ada. Studi literatur pada penelitian ini disusun dalam sebuah kajian pustaka yang membahas mengenai tanah 
longsor, stabilitas lereng, soil nailing, dan analisis shear strength reduction method menggunakan PLAXIS.

Penyusunan metode penelitian dilakukan agar proses penelitian menjadi lebih sistematis sesuai tahapan yang diperlukan untuk mengatasi suatu permasalahan. Pada penelitian ini, metode penelitian yang disusun berisi mengenai diagram alir penelitian beserta uraian penjelasannya.

c. Pengambilan data

Kegiatan pengambilan data merupakan suatu proses pencarian data yang diperlukan. Data yang diperoleh akan diolah dan menghasilkan suatu analisis. Data yang diambil pada penelitian ini berupa data peta lokasi, data penyelidikan tanah, stratigrafi lereng, dan data soil nailing.

Data peta lokasi dibuat sesuai kondisi di lapangan. Gambar 4 menunjukkan peta lokasi penelitian yang dilengkapi dengan letak cross section lereng yang akan dimodelkan serta letak titik pengujian bor yang digunakan.

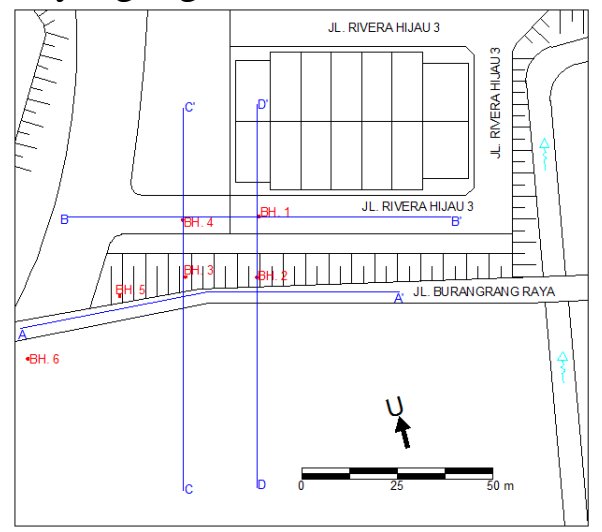

Gambar 4 Peta Lokasi Lereng Jalan Burangrang Raya

Data penyelidikan tanah menggunakan data sekunder yang diperoleh dari hasil pengeboran yang dilakukan oleh Laboratorium UNDIP. Penelitian ini meninjau cross section D-D' pada lereng yang memiliki dampak longsoran paling besar pada lokasi penelitian. Gambar 5 menunjukkan data hasil bor yang digunakan pada penelitian ini. Data hasil bor tersebut digunakan untuk membuat stratigrafi lereng dan menentukan parameter tanah. Stratigrafi lereng pada penelitian ini dapat dilihat pada Gambar 6. Parameter tanah untuk jangka pendek dapat dilihat pada Tabel 4, sedangkan untuk jangka panjang dapat dilihat pada Tabel 5.

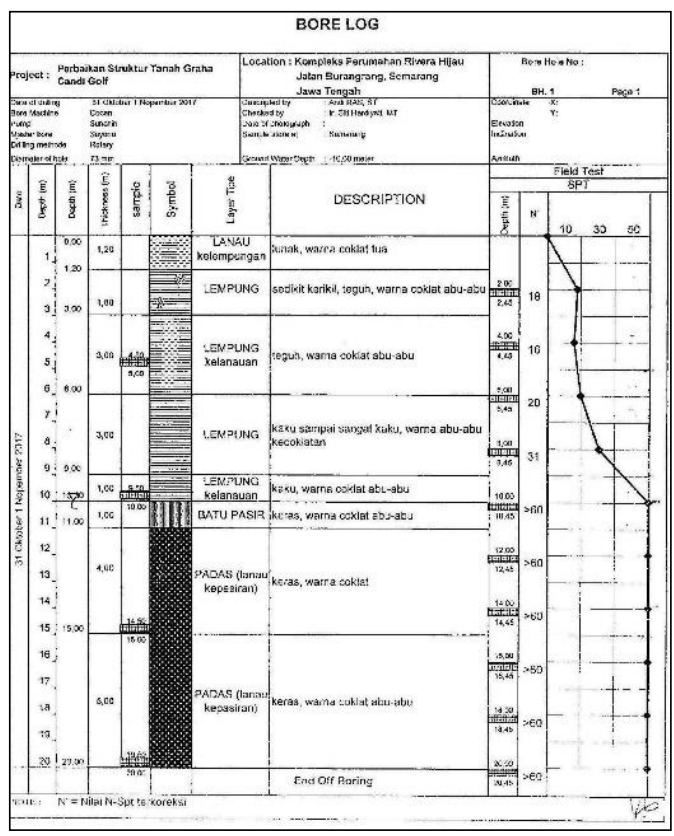

(a)Bore $\log$ BH. 1

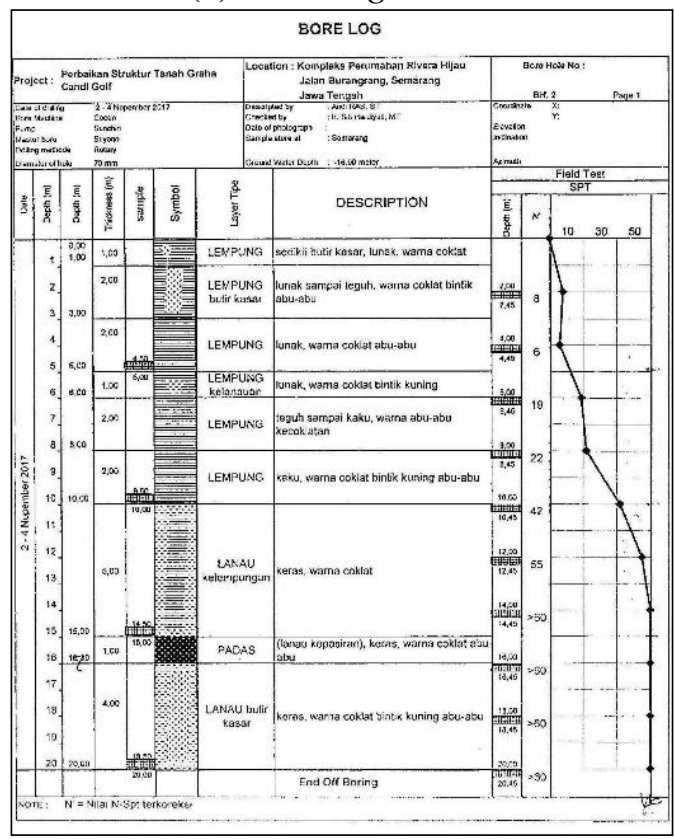

(b)Bore $\log$ BH. 2

Gambar 5 Bore Log di Lokasi

Penelitian (Sumber: Laboratorium Mekanika Tanah UNDIP, 2017 


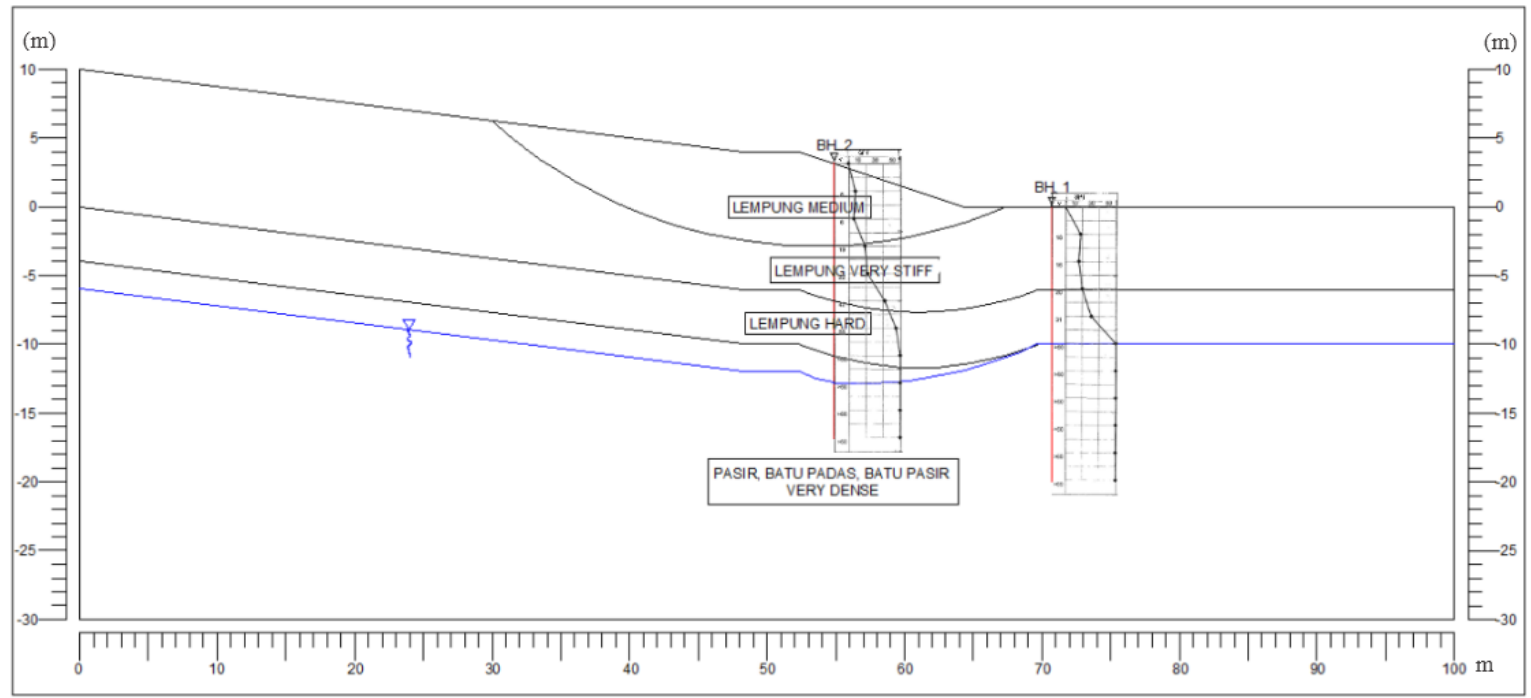

Gambar 6 Stratigrafi Lereng Cross Section D - D’

Tabel 4 Data Parameter Tanah untuk Jangka Pendek

\begin{tabular}{|c|c|c|c|c|c|c|c|c|c|c|c|c|}
\hline No & $\begin{array}{c}\text { Jenis } \\
\text { Tanah }\end{array}$ & $\begin{array}{l}\text { N- } \\
\text { SPT } \\
\text { rata- } \\
\text { rata }\end{array}$ & Kepadatan & $\begin{array}{c}\text { Tipe } \\
\text { Material }\end{array}$ & $\begin{array}{c}\gamma_{\text {unsat }} \\
\left(\mathbf{k N} / \mathbf{m}^{3}\right)\end{array}$ & $\begin{array}{c}\gamma_{s a t} \\
\left(\mathbf{k N} / \mathbf{m}^{3}\right)\end{array}$ & $\begin{array}{c}k \\
\text { (m/hari) }\end{array}$ & $e_{\text {initial }}$ & $\begin{array}{c}E \\
\left(\mathbf{k N} / \mathbf{m}^{2}\right)\end{array}$ & $v$ & $\begin{array}{c}c \\
\left(k N / m^{2}\right)\end{array}$ & $\begin{array}{l}\phi \\
\left({ }^{\circ}\right)\end{array}$ \\
\hline 1 & Lempung & 7 & Medium & Undrained & 17 & 18 & $8,64 \mathrm{E}-05$ & 1,3 & 10.000 & 0,25 & 15 & 20 \\
\hline 2 & Lempung & 18 & Very Stiff & Undrained & 18 & 19 & $8,64 \mathrm{E}-06$ & 1,2 & 55.000 & 0,35 & 75 & 23 \\
\hline 3 & Lempung & 39 & Hard & Undrained & 19 & 20 & $8,64 \mathrm{E}-04$ & 1 & 33.000 & 0,30 & 180 & 25 \\
\hline 4 & Padas & 60 & Very Dense & Drained & 20 & 21 & $8,64 \mathrm{E}-01$ & 0,9 & 42.000 & 0,30 & 5 & 41 \\
\hline
\end{tabular}

Tabel 5 Data Parameter Tanah untuk Jangka Panjang

\begin{tabular}{|c|c|c|c|c|c|c|c|c|c|c|c|c|}
\hline No & $\begin{array}{l}\text { Jenis } \\
\text { Tanah }\end{array}$ & $\begin{array}{c}\text { N-SPT } \\
\text { rata- } \\
\text { rata }\end{array}$ & $\begin{array}{c}\text { Kepadata } \\
\text { n }\end{array}$ & $\begin{array}{c}\text { Tipe } \\
\text { Material }\end{array}$ & $\begin{array}{c}\gamma_{\text {unsat }} \\
\left(\mathbf{k N} / \mathbf{m}^{3}\right)\end{array}$ & $\begin{array}{c}\gamma_{s a t} \\
(\mathbf{k N} / \mathbf{m} \\
3\end{array}$ & $\begin{array}{c}k \\
(\mathbf{m} / \mathbf{h a r i})\end{array}$ & $\boldsymbol{e}_{\text {initial }}$ & $\begin{array}{c}E \\
\left(\mathbf{k N} / \mathbf{m}^{2}\right)\end{array}$ & $v$ & $\begin{array}{c}c \\
\left(k N / m^{2}\right)\end{array}$ & $\begin{array}{c}\phi \\
\left({ }^{\circ}\right)\end{array}$ \\
\hline 1 & Lempung & 7 & Medium & $\begin{array}{l}\text { Draine } \\
d\end{array}$ & 17 & 18 & $\begin{array}{c}8,64 \mathrm{E}- \\
05\end{array}$ & 1,3 & 10.000 & 0,25 & 12 & 15 \\
\hline 2 & Lempung & 18 & Very Stiff & $\begin{array}{l}\text { Draine } \\
d\end{array}$ & 18 & 19 & $\begin{array}{c}8,64 \mathrm{E}- \\
06 \\
\end{array}$ & 1,2 & 55.000 & 0,35 & 60 & 18 \\
\hline 3 & Lempung & 39 & Hard & $\begin{array}{l}\text { Draine } \\
d\end{array}$ & 19 & 20 & $\begin{array}{c}8,64 \mathrm{E}- \\
04\end{array}$ & 1 & 33.000 & 0,30 & 144 & 20 \\
\hline 4 & Padas & 60 & $\begin{array}{c}\text { Very } \\
\text { Dense }\end{array}$ & Drained & 20 & 21 & $\begin{array}{c}8,64 \mathrm{E}- \\
01 \\
\end{array}$ & 0,9 & 42.000 & 0,30 & 4 & 33 \\
\hline
\end{tabular}

Data soil nailing berupa data pemasangan soil nailing dan parameter soil nailing. Pemasangan soil nailing dilakukan dengan variasi jumlah soil nailing sebanyak 2 baris, 3 baris, dan 5 baris. Data soil nailing dapat dilihat pada dengan posisi pemasangan dapat dilihat pada Gambar 7. 
Tabel 6 Data Soil Nailing

\begin{tabular}{|c|c|}
\hline Data Rencana Soil Nailing & Nilai \\
\hline Panjang (m) & 11 \\
\hline Diameter lubang, $D_{D H}(\mathrm{~mm})$ & 100 \\
\hline Diameter nail, $d(\mathrm{~mm})$ & 25 \\
\hline Kuat leleh nail, $f_{y}(\mathrm{MPa})$ & 390 \\
\hline Sudut inklinasi $\left({ }^{\circ}\right)$ & 65 \\
\hline Jarak antar nail horisontal (m) & 2 \\
\hline $\begin{array}{l}\text { Jarak antar nail vertikal (untuk } \\
\text { lereng dengan } \\
2 \text { soil nailing) (m) }\end{array}$ & 4,74 \\
\hline $\begin{array}{l}\text { Jarak antar nail vertikal (untuk } \\
\text { lereng dengan } \\
3 \text { soil nailing) (m) }\end{array}$ & 4,74 \\
\hline $\begin{array}{l}\text { Jarak antar nail vertikal (untuk } \\
\text { lereng dengan } \\
5 \text { soil nailing) (m) }\end{array}$ & 2,37 \\
\hline Data Parameter Soil Nailing & Nilai \\
\hline Luas soil nailing, $A\left(\mathrm{~mm}^{2}\right)$ & 7853,98 \\
\hline Luas nail, $A_{n}\left(\mathrm{~mm}^{2}\right)$ & 490,87 \\
\hline Luas grout, $A_{g}\left(\mathrm{~mm}^{2}\right)$ & 7363,11 \\
\hline $\begin{array}{l}\text { Modulus elastisitas nail, } E_{n} \\
(\mathrm{GPa})\end{array}$ & 200 \\
\hline $\begin{array}{l}\text { Modulus elastisitas grout, } E_{g} \\
(\mathrm{GPa})\end{array}$ & 22 \\
\hline $\begin{array}{l}\text { Modulus elastisitas grouted soil } \\
\text { nail, } E_{e q}(\mathrm{GPa})\end{array}$ & 33,12 \\
\hline Axial stiffness nail, EA (kN/m) & 130.061 \\
\hline $\begin{array}{l}\text { Bending stiffness nail, EI } \\
\left(\mathrm{kNm}^{2} / \mathrm{m}\right)\end{array}$ & 81,29 \\
\hline Berat soil nailing $(\mathrm{kN} / \mathrm{m} / \mathrm{m})$ & 0,094 \\
\hline Angka Poisson soil nailing & 0,2 \\
\hline
\end{tabular}

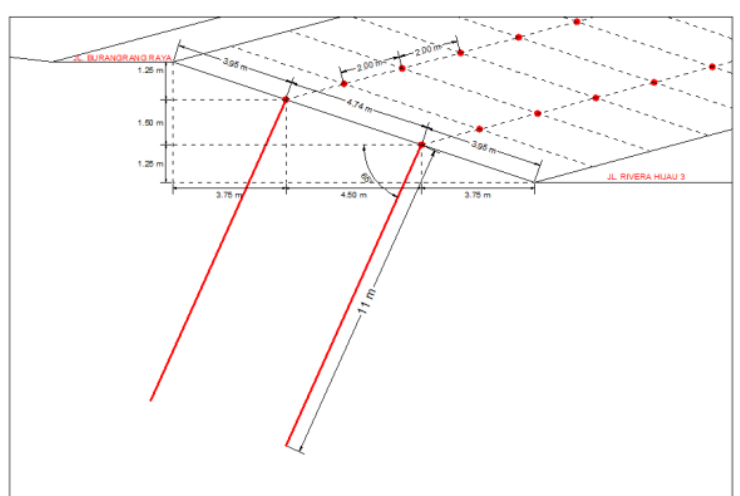

(a) Posisi Pemasangan 2 Baris Soil Nailing pada Lereng

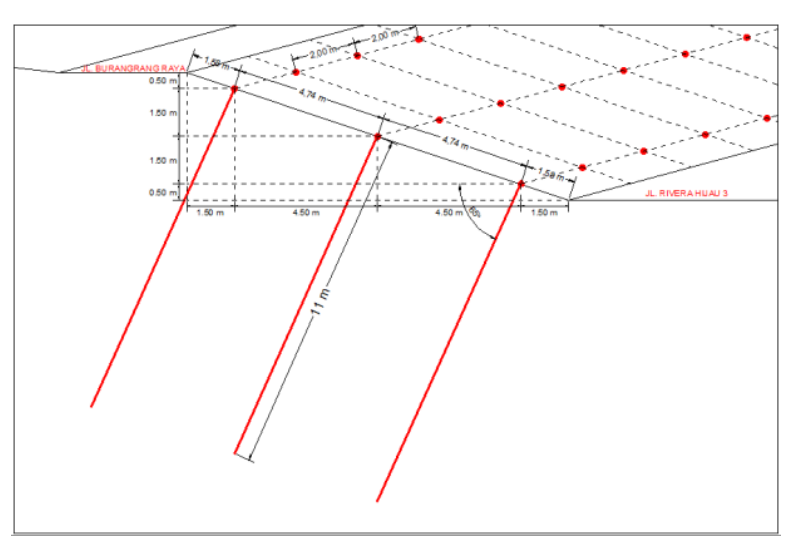

(b) Posisi Pemasangan 3 Baris Soil Nailing pada Lereng

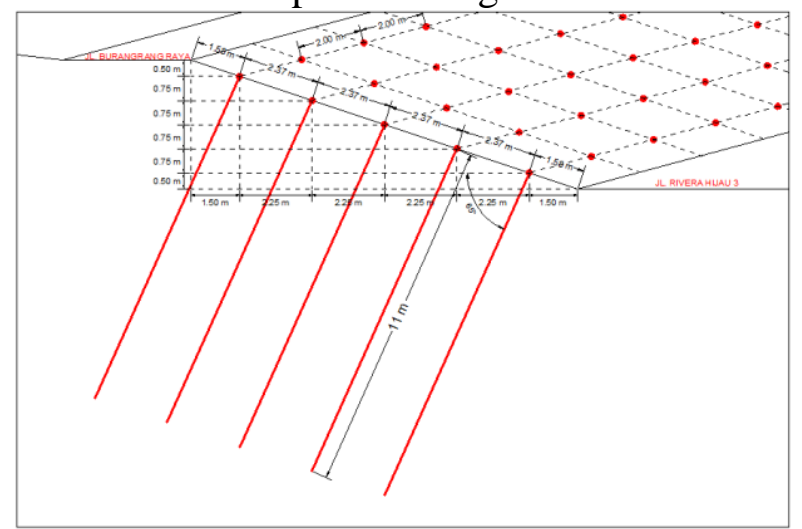

(c) Posisi Pemasangan 5 Baris Soil Nailing pada Lereng

Gambar 7 Posisi Pemasangan Soil Nailing pada Lereng 
d. Pemodelan menggunakan PLAXIS

Pemodelan dan analisis stabilitas lereng dilakukan menggunakan aplikasi PLAXIS. Pemodelan dibuat dengan 2 kondisi yaitu lereng dengan kondisi asli dan lereng dengan perkuatan soil nailing. Pada kondisi lereng dengan perkuatan soil nailing dilakukan analisis terhadap jangka pendek (selama konstruksi) dan jangka panjang (10 tahun setelah masa konstruksi berakhir).

Pemodelan stabilitas lereng menggunakan PLAXIS memerlukan input data yang sesuai agar dapat memberikan output yang benar. Tahapan input data pada PLAXIS untuk penelitian ini sebagai berikut:

d.1.Penggambaran model berupa stratigrafi lereng, bidang gelincir lereng, dan soil nailing.

d.2. Membuat kondisi batas model.

d.3. Membuat parameter tanah dan soil nailing dan dimasukkan pada model yang telah digambarkan.

d.4. Membuat jaring elemen pada lereng.

d.5. Membuat kondisi awal model.

Tahap kalkulasi data pada PLAXIS memiliki pengaturan utama yaitu sebagai berikut:

d.1.Pengaturan pemilihan tahapan sebelum tahapan yang dianalisis.

d.2.Pengaturan pemilihan tipe kalkulasi yang berupa analisis plastis, analisis konsolidasi atau analisis phi/c reduction.

d.3. Pengaturan analisis kondisi undrained atau drained serta selang waktu dan juga pengaturan model seperti pengaktifan soil nailing dan pengaktifan bidang gelincir.

\section{HASIL DAN PEMBAHASAN}

Pemodelan lereng asli dan lereng dengan perkuatan soil nailing menggunakan aplikasi PLAXIS ditunjukkan pada Gambar 8. Pada kondisi lereng asli, faktor keamanan lereng diperoleh sebesar 1,06. Lereng asli tersebut mengalami longsor yang diindikasikan dengan faktor keamanan yang kurang dari 1,2 .

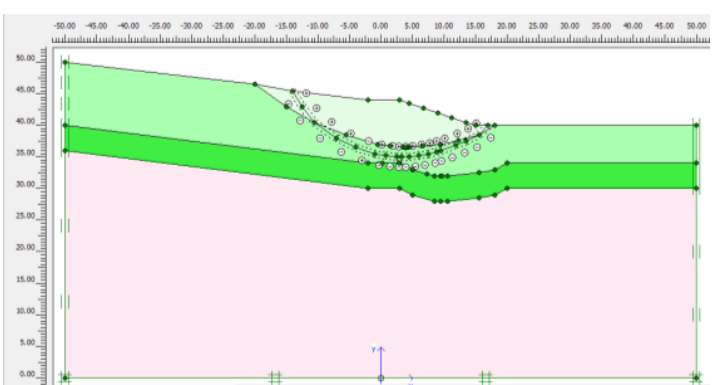

(a)Pemodelan Lereng Asli

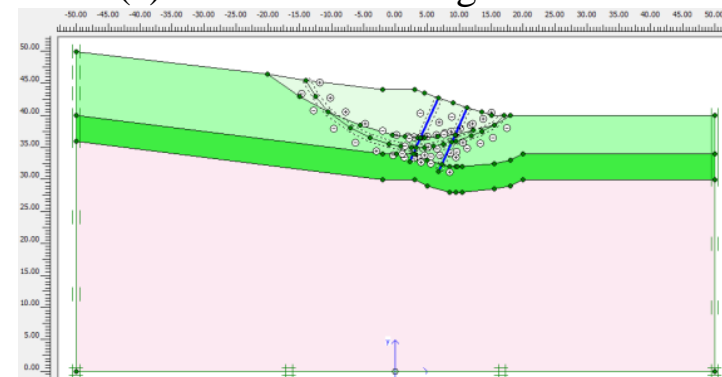

(b)Pemodelan Lereng dengan 2

Baris Soil Nailing

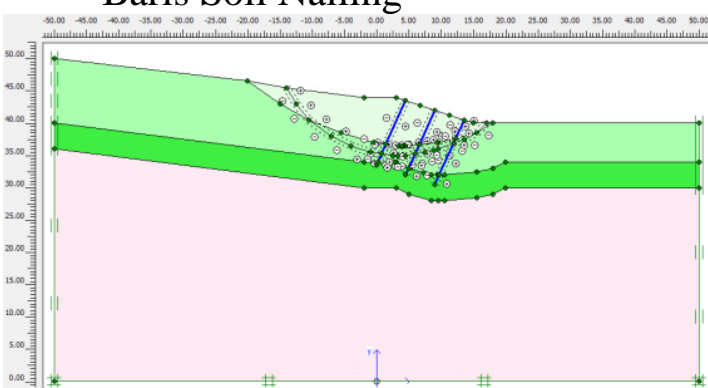

(c)Pemodelan Lereng dengan 3

Baris Soil Nailing 


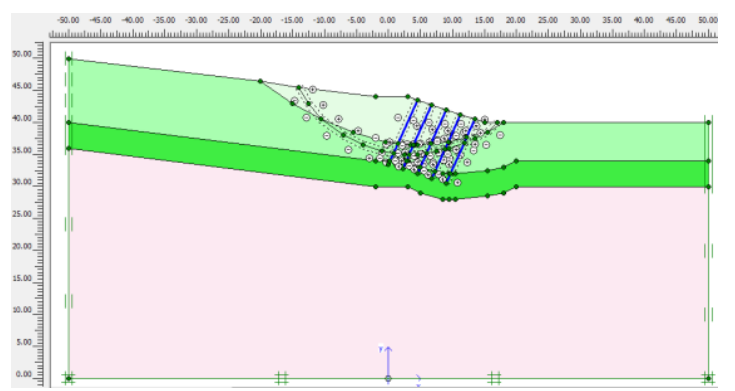

(d)Pemodelan Lereng dengan 5

Baris Soil Nailing

Gambar 8 Pemodelan Lereng Asli dan Lereng dengan Soil Nailing Menggunakan PLAXIS

Pada masa konstruksi (jangka pendek), pemasangan soil nailing pada lereng Jalan Burangrang Raya meningkatkan nilai faktor keamanan lereng lebih dari 3 kali nilai faktor keamanan lereng asli. Jumlah soil nailing yang dipasang mempengaruhi besarnya nilai faktor keamanan. Semakin banyak soil nailing terpasang, maka semakin besar juga nilai faktor keamanan yang lereng.
Lereng yang dipasang soil nailing cukup stabil selama kurun waktu 10 tahun (jangka panjang) dengan nilai faktor keamanan lebih dari

2 kali nilai faktor keamanan lereng asli. Faktor keamanan lereng dengan perkuatan soil nailing pada jangka pendek dan jangka panjang ditunjukkan pada Tabel 7. Peningkatan faktor keamanan lereng dengan perkuatan soil nailing dapat dilihat pada Gambar 9.

Tabel 7 Faktor Keamanan Lereng dengan Soil Nailing

\begin{tabular}{ccc}
\hline Jumlah Soil & \multicolumn{2}{c}{ Faktor Keamanan } \\
\cline { 2 - 3 } $\begin{array}{c}\text { Nailing } \\
\text { Terpasang pada } \\
\text { Lereng }\end{array}$ & $\begin{array}{c}\text { Jangka } \\
\text { Pendek }\end{array}$ & $\begin{array}{c}\text { Jangka } \\
\text { Panjang }\end{array}$ \\
\hline $\begin{array}{c}\text { 2 Baris Soil } \\
\text { Nailing }\end{array}$ & 3,18 & 2,31 \\
\hline $\begin{array}{c}\text { 3 Baris Soil } \\
\text { Nailing }\end{array}$ & 3,27 & 2,62 \\
\hline $\begin{array}{c}\text { 5 Baris Soil } \\
\text { Nailing }\end{array}$ & 3,43 & 2,76 \\
\hline
\end{tabular}

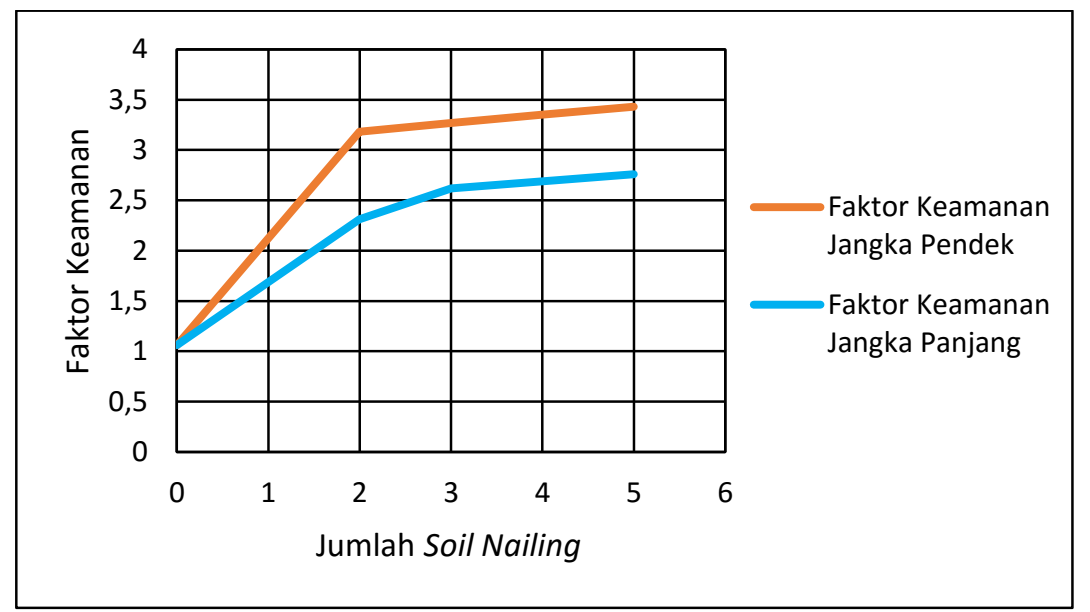

Gambar 8 Peningkatan Faktor Keamanan Lereng dengan Perkuatan Soil Nailing Soil Nailing 


\section{PENUTUP}

\subsection{Kesimpulan}

Penelitian dan pengolahan data yang telah dilakukan memberikan kesimpulan yang dirumuskan sebagai berikut:

a. Lereng pada Jalan Burangrang Raya memiliki potensi untuk mengalami kelongsoran kearah melintang jalan dengan nilai faktor keamanan sebesar 1,06 .

b. Nilai faktor keamanan lereng yang diperkuat soil nailing selama masa konstruksi dengan pemasangan soil nailing 2 baris, 3 baris, dan 5 baris secara berurutan diperoleh sebesar 3,18; 3,27; dan 3,43.

c. Nilai faktor keamanan lereng yang diperkuat soil nailing setelah 10 tahun dari akhir masa konstruksi dengan pemasangan soil nailing 2 baris, 3 baris, dan 5 baris secara berurutan diperoleh sebesar 2,31; 2,62; dan 2,76.

d. Berdasarkan hasil analisis yang telah dilakukan dapat disimpulkan bahwa semakin banyak soil nailing terpasang maka nilai faktor keamanan lereng semakin meningkat. Pemasangan soil nailing tersebut dapat meningkatkan nilai faktor keamanan hingga lebih dari 2 kali faktor keamanan lereng asli.

\subsection{Saran}

Sesuai dengan hasil penelitian dan pengolahan data yang telah dilakukan, saran yang dapat diberikan adalah sebagai berikut:

a. Parameter tanah yang digunakan untuk analisis sebaiknnya menggunakan hasil pengujian laboratorium sehingga hasil yang didapat lebih sesuai dengan kondisi lapangan. b. Penyelidikan tanah di lokasi sebaiknya ditambah dengan metode lain misalnya dengan uji geolistrik untuk cross check terhadap data yang sudah ada sehingga data yang digunakan untuk analisis menjadi lebih akurat.

c. Pemodelan yang dilakukan sebaiknya menggunakan lebih dari 1 data cross section sehingga akan diperoleh hasil analisis yang lebih mendalam.

d. Analisis stabilitas lereng dapat dicoba dengan perkuatan lainnya serta memperhitungkan drainase lereng, kondisi tanah ekspansif, dan beban luar seperti beban konstruksi dan beban lalu lintas agar hasilnya dapat dibandingkan.

e. Dianjurkan untuk memperhitungkan perubahan muka air yang terjadi pada lereng.

f. Apabila ingin ditambahkan kondisi rembesan maka sebaiknya menggunakan aplikasi bantu lainnya selain aplikasi PLAXIS.

g. Kekuatan soil nailing perlu dianalisis lebih mendalam menggunakan aplikasi lain misalnya menggunakan aplikasi ALLPILE.

\section{DAFTAR PUSTAKA}

Abramson, L.W., Lee, Thomas S., Sharma, S., Boyce, Gleen M., (2001): Slope Stability and Stabilization Methods, John Willey and Sons, New York.

Budiharjo, Liong Andreas Setiawan dan Mahardhika, David Christian, (2020): Tugas Akhir : Peningkatan Stabilitas Lereng dengan Soil Nailing Menggunakan Aplikasi PLAXIS, Unika Soegijapranta, Semarang. 
FHWA, (1993): FHWA-SA-93-026: Recommendations CLOUTERRE 1991; Soil nailing Recommendations - 1991 for Designing, Calculating, Constructing and Inspecting Earth Support Using Soil nailing, Federal Highway Administrtion, United States.

Hammah, R.E., Yacoub, T.E., Corkum, B.C., dan Curran, J.H., (2005): The Shear Strength Reduction Method for the Generalized Hoek-Brown Criterion, Symposium on Rock Mechanics (USRMS): Rock Mechanics for Energy, Mineral and Infrastructure Development, Northern Regions, Alaska.

Hardiyatmo, Hary Christady, (2010): Mekanika Tanah 2, Gajah Mada University Press, Yogyakarta.

Laboratorium Mekanika Tanah UNDIP, (2017): Proyek Perbaikan Struktur Tanah Graha Candi Golf, Lokasi Kompleks Perumahan Rivera Hijau Jalan Burangrang, Semarang, Jawa Tengah.

Nandi, (2007): Longsor, Handout mata kuliah Geomorfologi Jurusan Pendidikan Geografi, UPI, Bandung.

Peta lokasi Jalan Burangrang Raya diperoleh dari situs internet: https://www.google.co.id/maps/@$7.0382684,110.4369277,17 \mathrm{z} ? \mathrm{hl}=\mathrm{id}$. Diunduh pada tanggal 15 Juni 2019, pukul 20.00 WIB

Standards Australia, (2002): Australian Standardtm : Earth Retaining Structures, Council of Australia, Sydney. 